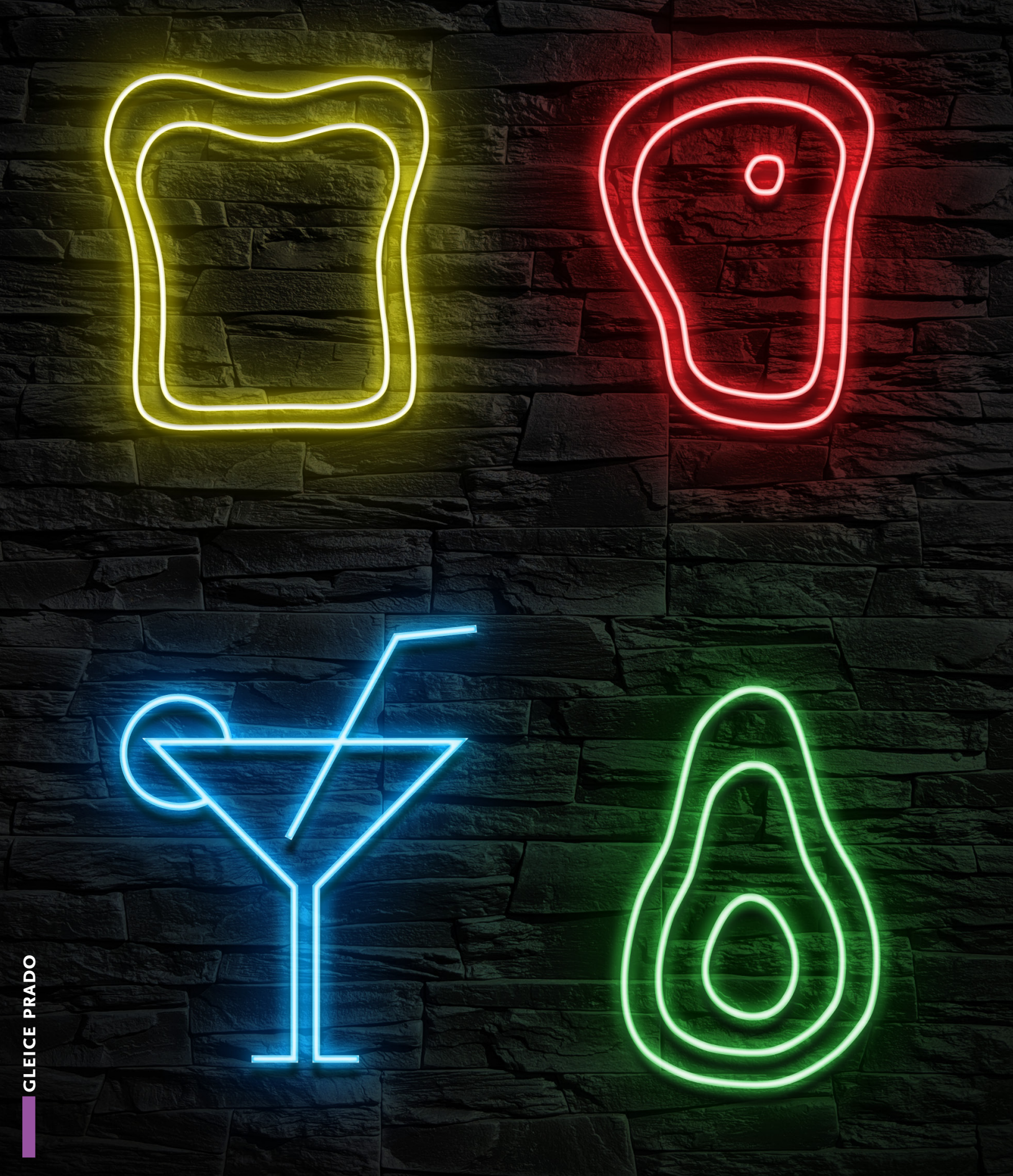




\section{ENERGIA EM BIOLOGIA}

ENIO CARDILLO VIEIRA*

RESUMO O alimento fornece energia para manutenção da vida. Carboidratos, lipídeos, proteínas e álcool são as principais fontes de energia, que fornecem, respectivamente, 4, 9, 4 e 7 quilocalorias por grama. A manutenção do peso ideal é importante para prevenção de doenças, que podem ser decorrentes da falta ou do excesso de energia ingerida. Deficiência de energia na criança causa marasmo e, no adulto, caquexia. Ingestão excessiva de energia promove obesidade, uma doença grave que predispõe a inúmeras outras doenças.

PalaVRas-chave Energia. Biologia. Metabolismo celular.

\section{ENERGY IN BIOLOGY}

ABSTRACT Food supplies energy for life maintenance. Carbohydrates, lipids, proteins, and alcohol are the main sources of energy producing, respectively, 4, 9, 4, and 7 kilocalories per gram. The maintenance of the ideal body weight is very important. Lack of energy in children and adults leads to marasmus and caquexia, respectively. Excessive ingestion of energy causes obesity, a severe disease that predisposes to several other diseases.

KEYwORDs Energy. Biology. Cell metabolism.

* Professor Emérito de Bioquímica, Instituto de Ciências Biológicas, Universidade Federal de Minas Gerais (UFMG) enio.cardillo@terra.com.br 


\section{Aspectos gerais}

nutrição é uma ciência baseada na química que trata de processos químicos e
fisiopatológicos, os quais, por sua vez, transformam os nutrientes em elementos corporais. A nutrição é um dos fatores ambientais que têm uma influência significativa sobre a habilidade dos seres vivos em atingir seu potencial genético pleno para crescimento, reprodução, saúde, longevidade e resposta a estímulos.

A nutrição, para todos os seres vivos, cumpre duas finalidades principais: fornecimento de energia e suprimento de substâncias essenciais ao organismo. Uma terceira finalidade ligada ao ato de se alimentar pode ser acrescentada: obtenção de prazer por meio da alimentação.

O alimento fornece ao organismo sete componentes: energia, proteínas, lipídeos, carboidratos, vitaminas, sais minerais e fibras. Água e oxigênio, cujos papéis na manutenção da vida são óbvios, poderiam ser acrescentados à relação de nutrientes.

\section{Fontes de energia}

Os principais componentes dos alimentos que fornecem energia são proteínas, lipídeos e carboidratos, que produzem, respectivamente, 4, 9 e $4 \mathrm{kcal} / \mathrm{g}$. Os produtos da digestão são absorvidos e utilizados em processos metabólicos diversos para produção de energia ou para armazenamento. Outros componentes eventuais dos alimentos, como citrato, acetato e outros ácidos orgânicos, são metabolizados e fornecem energia. As bebidas alcoólicas contribuem para o aporte energético para grande parte da população. O álcool (etanol) fornece $7 \mathrm{kcal} / \mathrm{g}$. 


\section{Unidades}

A unidade de medida de energia, internacionalmente recomendada, é o joule. A conversão de caloria em joule faz-se pela equivalência:

I $\mathrm{cal}=4, \mathrm{I} 8$ joules.

Em nutrição, usa-se a quilocaloria (kcal), que equivale a r.000 cal. Caloria é a energia necessária para elevar a temperatura da água em um grau centígrado $\left(\mathrm{I} 4,5{ }^{\circ} \mathrm{C}\right.$ a $\left.15,5^{\circ} \mathrm{C}\right)$. Na linguagem popular, o termo caloria confunde-se com energia. Assim, fala-se de alimentos que fornecem muitas ou poucas calorias.

\section{Necessidades}

Quais são as demandas diárias de energia para o homem adulto? A resposta mais simples a essa pergunta é a seguinte: aquela quantidade de energia necessária para manutenção do peso ideal. A necessidade de energia depende de diversas variáveis: idade, sexo, massa corporal, estado fisiológico, atividade física e fatores individuais.

A Tabela I mostra as recomendações dietéticas de acordo com a National Academy of Sciences e o National Research Council dos Estados Unidas. Observam-se as diferenças nas recomendações para pessoas de idades e sexos diferentes e, ainda, os acréscimos que se devem fazer para gestantes e nutrizes.

Há que se distinguir necessidade de recomendação. Necessidade é a quantidade mínima de um determinado nutriente para manutenção da saúde. Essa necessidade baseia-se em extrapolações derivadas de dados de experiências com animais. As recomendações estão acima dos valores das necessidades para se garantir uma margem de segurança de modo a evitar deficiências decorrentes de variações individuais.

A necessidade de energia diminui quando se passa da idade adulta. À medida que a idade avança, a necessidade de energia diminui. Esse fato explica por que muitas pessoas engordam na maturidade. A necessidade de energia é maior para o homem do que para a mulher. Quanto maior a massa corporal, maior a necessidade energética. A superfície corporal mostra um paralelismo mais estreito com a necessidade energética do que o peso corporal. A necessidade de energia está relacionada com estados fisiológicos. 


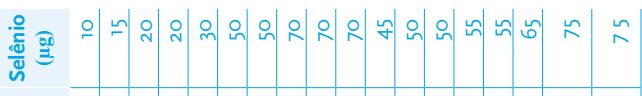

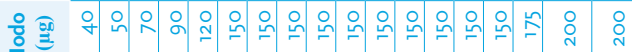

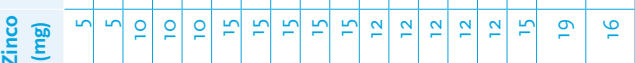

离

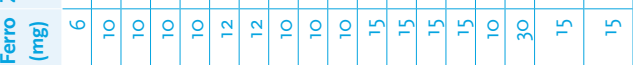

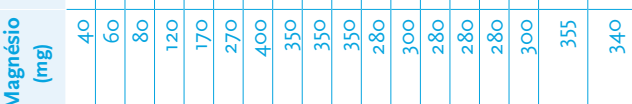

离离

苑

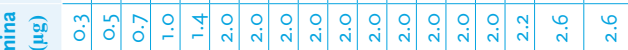

$\sum^{\frac{\pi}{2}}$

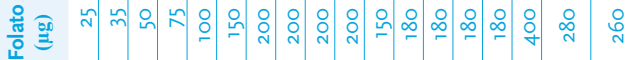

焉西

劳

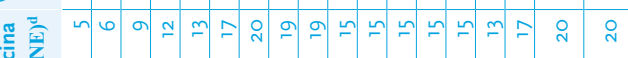

要觉

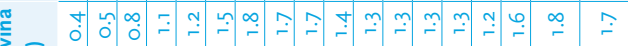
望

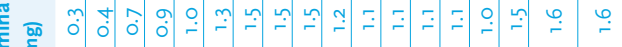

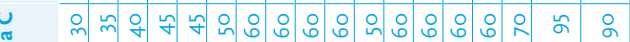

垔

>

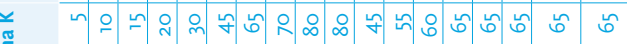

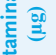

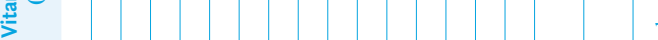

ш

空药

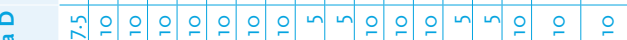

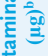

象

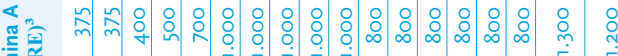

密哭

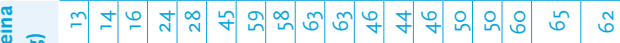
政

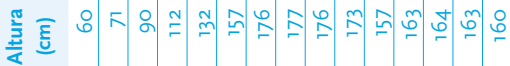

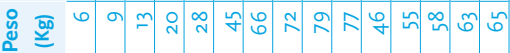

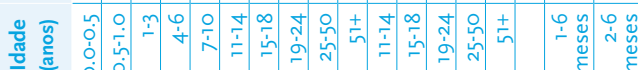

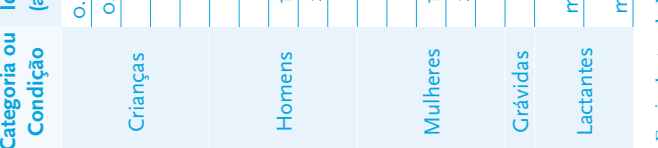


Na gravidez, na lactação e em idades em que o surto de crescimento é grande, há aumento na demanda de energia. A necessidade de energia está diretamente relacionada com a atividade física: quanto mais intensa é a atividade, maior é a necessidade energética. A Tabela 2 mostra as demandas de energia para o exercício de atividades diárias diversas. Uma variável importante reside nos fatores individuais. Assim, dois indivíduos do mesmo sexo, da mesma idade, com o mesmo peso e fazendo a mesma atividade física podem ter necessidades energéticas diferentes, cuja expressão se encontra na equação:

Necessidade energética $=$ metabolismo basal + termogênese + atividade física

Tabela 2 - Gasto em calorias, em atividaes físicas diversas Gasto energético em calorias, em 10 minutos de atividades físicas diversas

\begin{tabular}{l|r|r|r|r|r}
\hline Atividade & 57 & 68 & 80 & 90 & 115 \\
\hline Dormindo & 10 & 12 & 14 & 16 & 20 \\
\hline Em pé & 12 & 14 & 16 & 19 & 24 \\
\hline Descer escadas & 56 & 67 & 78 & 88 & 111 \\
\hline Subir escadas & 146 & 175 & 202 & 229 & 288 \\
\hline Caminhar 6km/h & 52 & 62 & 72 & 81 & 102 \\
\hline Correr 10 km/h & 118 & 141 & 164 & 187 & 232 \\
\hline Bicicleta 20 km/h & 89 & 107 & 124 & 142 & 178 \\
\hline Trabalho doméstico & 34 & 41 & 47 & 53 & 68 \\
\hline Lavar chão & 38 & 46 & 53 & 60 & 75 \\
\hline Cozinhar & 32 & 39 & 46 & 52 & 65 \\
\hline Escrever sentado & 15 & 18 & 21 & 24 & 30 \\
\hline Mecânica de automóvel & 35 & 42 & 48 & 54 & 69 \\
\hline Voleibol & 43 & 52 & 65 & 75 & 94 \\
\hline Basquetebol & 58 & 70 & 82 & 93 & 107 \\
\hline Futebol & 69 & 83 & 96 & 110 & 137 \\
\hline Dança Moderada & 35 & 42 & 48 & 55 & 69 \\
\hline Dança movimentada & 48 & 57 & 66 & 75 & 94 \\
\hline Pingue-pongue & 32 & 38 & 45 & 52 & 64 \\
\hline Natação(2om/min) & 32 & 38 & 45 & 52 & 64 \\
\hline Tênis & 56 & 67 & 80 & 92 & 115 \\
\hline
\end{tabular}

Fonte: Food and Nutrition Board, National Academy of Sciences - National Research Council, USA.

\section{Metabolismo Basal}

O metabolismo basal varia de um indivíduo para outro. Representa a energia necessária para manutenção dos processos vitais. As células trabalham 24 horas por dia. Esse gasto de energia ocorre mesmo que o indivíduo se encontre em repouso absoluto. Estima-se que cerca de dois terços do gasto diário de energia sejam representados pelo metabolismo basal.

A bomba de sódio é responsável por 20-30\% do gasto energético do metabolismo basal. Isso significa que o organismo gasta grande quantidade de energia para 
Figura 1 - Ciclos fúteis
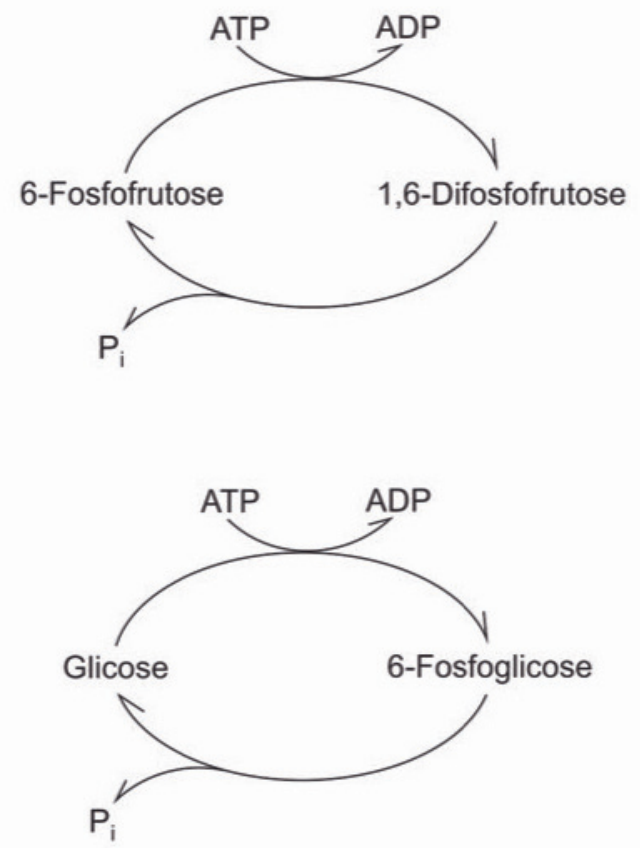

Em cada volta do ciclo, há consumo de uma molécula de ATP. Fonte: VIEIRA, EC, FIGUEIREDO, EA, ALVAREZ-LEITE, Jl et al., 1995, p. 247. manutenção do sódio fora da célula. Essa quantidade de energia varia de indivíduo para indivíduo. Demonstrouse que pessoas com dificuldades de perder peso ou animais geneticamente obesos têm bomba de sódio mais eficiente, isto é, mantêm o sódio fora da célula com um dispêndio menor de energia. Isso explicaria a dificuldade que certos pacientes obesos têm para perder peso a despeito de reduções apreciáveis no aporte calórico (ERDMAN JUNIOR; MACDONALD; ZEISEL et al., 20I2).

Outra contribuição importante para o metabolismo basal é dada pelos chamados ciclos fúteis. Exemplos de ciclos fúteis encontram-se na Figura I. A fosforilação de alguns compostos consome ATP, e a desfosforilação deles leva-os ao ponto inicial. Quanto maior a intensidade dos ciclos fúteis, maior será o gasto sem aproveitamento de energia. Não se conhece, precisamente, a contribuição dos ciclos fúteis para o gasto de energia.

\section{Termogênese}

Termogênese é a produção de calor no organismo. Há dois tipos de termogênese: adaptativa ou reguladora e induzida pela dieta.

A termogênese reguladora ou adaptativa, ainda conhecida como termogênese sem tremores, é responsável pela geração de calor no organismo. Ela torna possível a adaptação do animal às variações de temperatura ambiente. Esse tipo de termogênese é particularmente importante em animais que sobrevivem em temperaturas muito baixas, sobretudo durante o período de hibernação. Esses animais têm quantidades apreciáveis de tecido adiposo pardo.

A termogênese induzida pela dieta reflete a produção de calor que acompanha a ingestão de alimentos. Mastigação, produção de enzimas digestivas, absorção, deposição dos produtos da digestão requerem energia. É também chamada de ação dinâmica específica. Acreditava-se haver diferenças na ação dinâmica específica de acordo com o tipo de alimento ingerido. Sabe-se que dietas diferentes influem muito pouco em seu valor. 


\section{Atividade física}

A atividade física é um fator muito variável. O requerimento energético de diversos tipos de exercícios está mostrado na Tabela 2.

A Figura 2 mostra a contribuição relativa do metabolismo basal, da termogênese e da atividade física no gasto total de energia de um adulto sedentário. Observa-se a maior participação do metabolismo basal e a pequena contribuição da atividade física. Mostrou-se que a atividade física aumenta o metabolismo basal. Esse efeito persiste por I5 horas. Assim, se um indivíduo faz exercício pela manhã, seu metabolismo basal está mais elevado à noite. É importante que o indivíduo se mantenha em atividade física durante toda a vida. O exercício físico é importante na prevenção de diversas doenças. Descrevem-se mais de trinta benefícios para a saúde (KAMEN, 200I), inclusive na prevenção de câncer (WCRF-AICR, 20I7). A manutenção da atividade física é importante para a prevenção de sarcopenia (diminuição da massa muscular).
Figura 2- Componentes do gasto de energia

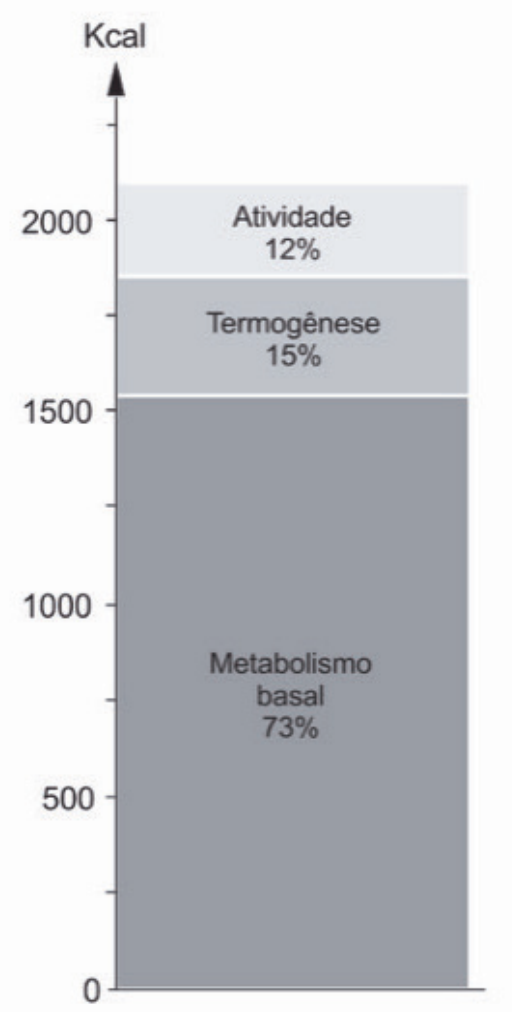

Fonte: VIEIRA, EC, FIGUEIREDO, EA, ALVAREZ-LEITE, Jl et al., 1995 , p. 248.

\section{Balanço energético}

O homem, à semelhança de todos os seres vivos, obedece à primeira lei da termodinâmica, a lei da conservação de energia. Animais armazenam energia na forma de gordura. Já os vegetais armazenam energia em carboidratos. A ingestão de energia além do necessário resulta no aumento do tecido adiposo. Se a ingestão de energia está aquém das necessidades, os animais mobilizam as reservas energéticas - as gorduras - para suprimento da deficiência. 


\section{Deficiência de ingestão de energia}

A Organização Mundial de Saúde considera que o problema nutricional maior no mundo é o da quantidade de alimento. Acredita-se que, se houver alimento em quantidade suficiente para atender às necessidades energéticas, é muito provável que as necessidades de nutrientes sejam satisfeitas, inclusive a de proteínas.

A deficiência na ingestão de energia provoca a caquexia no adulto e o marasmo na criança. $\mathrm{O}$ adulto caquético é exageradamente magro e anêmico e torna-se apático. A hipoalbuminemia é responsável por edema - edema de fome - que se instala. A criança marasmática é esquálida e apática. O emagrecimento é acentuado. A apatia é consequência da deficiência calórica e representa uma defesa do organismo na tentativa de economizar energia. No marasmo, existe uma policarência, isto é, deficiência de muitos nutrientes.

\section{Excesso de ingestão energética}

O excesso de ingestão de energia resulta na obesidade, que é o resultado do acúmulo de gordura no tecido adiposo. Há muitos conceitos falsos e muitas crendices a respeito dessa doença. O que causa obesidade é o excesso de energia ingerida, independentemente da sua origem. Em outras palavras, proteínas, gorduras e carboidratos produzem energia e, portanto, ingeridos em excesso, podem engordar. O organismo não distingue calorias fornecidas por carboidratos daquela proveniente de proteínas ou de gorduras. O custo metabólico para a conversão de gordura dietética em gordura corporal é de cerca de $3 \%$ da energia ingerida. Por outro lado, o custo metabólico para conversão de carboidratos em gorduras chega a $26 \%$ da energia ingerida. Deduz-se daí que a gordura da dieta favorece mais o acúmulo de gordura corporal do que o de carboidrato, por um fator maior do que 8. Países onde há maior prevalência de obesidade são aqueles onde o consumo de gordura é muito elevado. Já no Oriente, onde a base da alimentação é o arroz - alimento rico em carboidrato -, a incidência de obesidade é baixa.

A prevalência de obesidade está aumentando em todo o mundo. Em algumas regiões do planeta, chegou a quadruplicar (POPKIN; ADAIR.; NG., 20I2). Obesidade é uma doença temível. Inúmeras causas de morte afetam mais o indivíduo obeso quando comparado com o magro. 


\section{Aporte de energia e longevidade}

McCay e colaboradores (I935), em experiências clássicas, mostraram que ratos mantidos com ingestão calórica baixa, isto é, ingerindo menos alimento do que o fariam nas condições normais de laboratório, viviam mais do que seus pares alimentados ad libitum. Esses dados foram confirmados por inúmeros autores em diversas espécies animais. Claro que a ética não permitiria a execução de experiências desse tipo em seres humanos. Contudo, há um dado interessante. A maior proporção de centenários no mundo vive em uma ilha do Japão: Okinawa (DIRKS \& LEEUWENBURGH, 2006). A população dessa ilha ingere os mesmos alimentos consumidos por japoneses de outras ilhas. Contudo, por tradição, a população nessa ilha consome menor quantidade de alimentos quando comparada com a ingestão de alimentos por japoneses de outras ilhas. Atualmente, estudam-se experimentalmente os tipos de nutrientes cuja diminuição afeta a longevidade e a faixa etária em que essa diminuição é mais eficaz para aumentar o tempo de vida dos animais. De qualquer forma, permanece a ideia segundo a qual, havendo parcimônia na ingestão de alimentos, investe-se em longevidade.

\section{Referências}

DIRKS, A. J.; LEEUWENBURGH, C. Caloric Restriction in Humans: Potential Pitfalls and Health Concerns. Mechanisms of Ageing and Development, v. I27, n. I, p. I-7, jan. 2006. DOI: https://doi. org/I0.IoI6/j.mad.2005.09.00I

ERDMAN JUNIOR., J. W.; MACDONALD, I. A.; ZEISEL, S. H. (edit.). Present Knowledge in Nutrition. ıo. ed. Oxford: Wiley, Blackwell, $20 \mathrm{I2}$.

KAMEN, G. Foundations of Exercise Philadelphia: Lippincottt, Williams \& Wilkins, 200I.

MCCAY, C. M.; CROWELL, M. F.; MAYNARD, L. A . The Effect of Retarded Growth upon the Length of Life Span and upon the Ultimate Body Size. The Journal of Nutrition, v. Io, n. I, p. 63-79, jul. I935. DOI: https://doi.org/I0.I093/jn/ı..I.63

POPKIN, B. M.; ADAIR, L. S.; NG, S. W. Global nutrition transition and the pandemic of obesity in developing countries. Nutrition Reviews, v. 70, n. I, p. 3-2I, jan. 2012

VIEIRA, E.C.; FIGUEIREDO, E.A.; ALVAREZ-LEITE, J.I.; GOMEZ, E.C. Química Fisiológica. 2. ed. Rio de Janeiro: Atheneu, I995.

WORLD CANCER RESEARCH FUND, AMERICAN INSTITUTE FOR CANCER RESEARCH -WCRF/AICR. Food, Nutrition, Physical Activity, and the Prevention of Cancer: A Global Perspective. WCRT/AICR, 2007 . 